\title{
Periodic Breathing and Apnea in Preterm Infants
}

\author{
KEITH J. BARRINGTON AND NEIL N. FINER \\ University of Alberta, Division of Paediatric Critical Care, and Royal Alexandra Hospitals, Department of \\ Newborn Medicine, Edmonton, Alberta, Canada
}

\begin{abstract}
The relationship between periodic breathing and idiopathic apnea of prematurity was investigated. We recorded respiratory impedance, heart rate, pulse oximetry and end-tidal $\mathrm{CO}_{2}$ from 68 untreated infants of less than or equal to 34 wk gestation with a diagnosis of idiopathic apnea of prematurity. Mean birth wt was $1476 \mathrm{~g}$ (SD 420) and mean gestational age was 29.9 wk (SD 2.6). Apneas of more than $15 \mathrm{~s}$ duration that were associated with hypoxemia or bradycardia were identified by semiautomated analysis of computerized records. A total of 1116 significant apneic spells were identified, only one of which occurred during an epoch of periodic breathing, five others occurred within 2 min of the end of an epoch of periodic breathing. Less than $0.6 \%$ of significant apneic spells occur within 2 min of periodic breathing. In all of the 12 infants that were monitored starting in the first $12 \mathrm{~h}$ or life, significant apneic spells were identified before $36 \mathrm{~h}$ of age and no precipitating factors were identified. Periodic breathing did not occur during the first $48 \mathrm{~h}$ of life, a finding that supports the concept that the peripheral chemoreceptor is inactive in the first $48 \mathrm{~h}$ of life. Periodic breathing in the premature infant is not a precursor to significant apnea. (Pediatr Res 27: 118-121, 1990)
\end{abstract}

It is commonly stated (1-3) that periodic breathing is closely associated with apnea of prematurity. This belief appears to date from a landmark article by Daily et al. (4), which was the first publication dealing with their experience with impedance pneumography, in which it was stated that all of the apneas in their monitored premature infants occurred during expiration in periodic breathing.

Periodic breathing can be produced in neonatal guinea pigs by suppression of the central chemoreceptor and then terminated by removing peripheral chemoreceptor influence (5). This suggests that periodicity depends on activity of the peripheral chemoreceptors and theoretical models suggest that it is caused by an imbalance between the central and peripheral chemoreception influences on respiratory drive (6).

Arousal from prolonged apneic spells appears to require active peripheral chemoreceptor function in adult dogs (7) and also during active sleep in newborn lambs (8). Thus, prolonged apneas associated with failure to terminate spells should be more frequent when the carotid chemoreceptor is quiescent.

In response to a brief hyperoxic challenge [the Dejours test (9)] the term newborn does not exhibit significant hypoventilation until after the first $48 \mathrm{~h}$ of life, a finding that implies that the peripheral chemoreceptors are suppressed at this time (10).

We reasoned that periodic breathing in the newborn preterm

Received June 8, 1989; accepted October 2, 1989.

Correspondence and reprint requests Keith J. Barrington, Neonatal ICU, 3A3 Walter Mackenzie Centre, University of Alberta Hospitals, Edmonton, Alberta, Canada, T6G 2R7.

Supported by a grant from the Northern Alberta Children's Hospital Foundation. infant is dependent on function of the peripheral chemoreceptors (11), which are inactive immediately after birth. We also reasoned that termination of apneas relies on peripheral chemoreceptor function and that apneic spells would be rapidly terminated and less likely to become prolonged, or "significant," when peripheral chemoreceptor function is prominent.

We therefore hypothesized that periodic breathing would be absent during the first $48 \mathrm{~h}$ of life. We further hypothesized that apneic spells would be absent when periodic breathing is occurring. Our objective, therefore, was to determine the frequency with which apneic spells are immediately preceded by periodic breathing, and the natural history of the postnatal appearance of periodic breathing and apnea.

\section{MATERIALS AND METHODS}

Newborn infants who were without significant respiratory disease (i.e. spontaneous respiration, $\mathrm{FIO}_{2}$ less than $30 \%$ to maintain $\mathrm{PaO}_{2} 60$ to 80 torr, no significant findings on chest radiograph) and who were less than $34 \mathrm{wk}$ gestation were eligible for entry into the study.

All had negative investigations for sepsis, electrolyte, or blood sugar disturbance. Infants in whom cranial ultrasound revealed significant intracranial pathology (i.e. periventricular leukomalacia, intracerebral haemorrhage, or intraventricular haemorrhage that distended the lateral ventricles) were excluded from the study.

Sixty-eight infants were studied, 56 infants were entered because of a clinical suspicion that they were having apnea of prematurity. This group was designated the later monitored group. Another group of 12 infants was entered during the first $12 \mathrm{~h}$ of life without any clinical suspicion of apnea, and designated the early monitored group. These 12 infants satisfied the same admission criteria as the other 56 infants, and when significant apnea became clinically evident the same investigations for precipitants of apnea were performed. No infant received theophylline, doxapram, or continuous positive airway pressure during the study period.

Heart rate, impedance pneumogram, end-tidal $\mathrm{CO}_{2}$, and pulse oximeter were continuously recorded in all infants using a computerized data acquisition system (12). Transcutaneous $\mathrm{PO}_{2}$ was also monitored in 30 of the infants. The digitized signals from these devices were stored on hard disk for later semiautomated analysis.

Significant apnea was defined as a cessation of nasal airflow of $15 \mathrm{~s}$ or more if associated with either a fall in heart rate of at least $20 \%$ from the previous baseline or a fall in saturation of at least $10 \%$. Significant apneas were further subdivided into central, without respiratory efforts or detectable expired $\mathrm{CO}_{2}$; obstructive, with continued respiratory effort in the absence of detectable expired $\mathrm{CO}_{2}$ throughout the apnea; and mixed, which were significant apneas with both central and obstructive components. Periodic breathing was defined as three or more cyclical apneas of $\geq 3 \mathrm{~s}$ in duration separated by regular respirations of less than $20 \mathrm{~s}$. 
The recording of each infant continued until they were treated with theophylline, doxapram, continuous positive airways pressure, positive pressure ventilation or until $1 \mathrm{wk}$ had passed, whichever was the shorter. Oxygen was required in three infants in order to maintain $\mathrm{PaO}_{2}$ above 60 torr. Oxygen was only used to correct hypoxemia and was not used as a therapy for apneic spells. Infants receiving oxygen were carefully monitored to eliminate the possibility of hyperoxia.

Each record was scanned by a purpose written program until a probable significant apnea was identified. The algorithm for the detection of apnea flagged any 2-min epoch in which there were any two of the following: fall in transcutaneous $\mathrm{PO}_{2}$ of 5 torr over less than $1 \mathrm{~min}$; fall in pulse oximeter of $5 \%$ over less than $30 \mathrm{~s}$; absence of end-tidal tracing for more than $10 \mathrm{~s}$; fall in heart rate of more than $10 \%$ below the previous mean. Individual flagged epochs were then inspected to eliminate artefact, and to confirm the presence and nature of the apneic spell. Preliminary comparisons of this method with the visual inspection of paper recordings, revealed that all of the significant apneic spells were identified with a marked reduction in operator time. If the episode satisfied our stated definition of a significant apneic spell, then the preceding $2 \mathrm{~min}$ of the record was also inspected to determine the presence or absence of periodicity. We therefore created a data base that included the time, nature, and duration of the apneic spell, and the association of each spell with periodic breathing. If an associated epoch of periodic breathing was found, the precise nature of the relationship was described.

Finally, we determined the overall prevalence of periodic breathing independent of the occurrence of significant apneic spells. The records of all of the infants were examined from the beginning of the study until the appearance of the first significant apneic spell. In all cases the early monitored infants had apneic spells before $36 \mathrm{~h}$ of age, their records were therefore examined for the first $48 \mathrm{~h}$ of life. We noted the time of the commencement of each epoch of periodic breathing and its duration. The total duration of the periodic epochs was divided by the length of the record that was examined and the results is referred to as the prevalence of periodicity.

The recordings were not available to the staff involved in the clinical management of the infants and intervention for termination of individual spells and for the therapy of apnea continued according to the usual nursery practice. Individual spells were resuscitated when the bedside alarm systems alerted the nursing staff to the occurrence of an apneic spell. Intervention consisted of a progression through gentle shaking and vigorous stimulation to positive pressure ventilation with a face mask.

The noninvasive recordings were obtained with the approval of the Clinical Research Committee of the Royal Alexandra Hospitals, specific informed consent was not required.

\section{RESULTS}

The mean birthwt of the 68 infants was 1476 (SD 420) (range 710 to 2205) and the mean gestational age was 29.9 (SD 2.6) wk (range 26 to 34 ). The mean postnatal age at the time of initiation of monitoring of the infants studied within $12 \mathrm{~h}$ of birth was 4.7 (SD 0.8 ) $\mathrm{h}$ (range 1.2 to 12 ), the mean postnatal age of the remaining 56 infants was 110 (SD 60) h. All of the infants in both the early monitored group and the later monitored group had negative investigations for precipitants of apnea.

A total of 1116 significant apneic spells was identified (Table 1). All of the infants exhibited central and mixed apneic spells and all except two, both later monitored infants, also had purely obstructive events. The incidence of apneas varied from $0.5 / \mathrm{h}$ to $4.2 / \mathrm{h}$ (Fig. 1). There was no correlation between the apnea frequency and the prevalence of periodic breathing (Pearson correlation coefficient $=0.3, p=\mathrm{NS}$ ).

Only one significant apneic spell occurred during periodic breathing. Five further apneic spells occurred during the 2 min after termination of an epoch of periodic breathing. The remain-
Table 1. Distribution and frequency of aqpnea types

\begin{tabular}{lcccc}
\hline & $\begin{array}{c}\text { Percentage } \\
\text { of } \\
\text { total } \\
\text { apneas }\end{array}$ & $\begin{array}{c}\text { Mean } \\
\text { duration } \\
\text { (range) s }\end{array}$ & $\begin{array}{c}\text { No. of } \\
\text { infants with } \\
\text { this type }\end{array}$ & $\begin{array}{c}\text { Mean } \\
\text { frequency/h } \\
\text { (range) }\end{array}$ \\
\hline Central & 43 & $27.9(15-103)$ & 68 & $0.7(0.2-1.9)$ \\
Mixed & 48 & $28.4(15-59)$ & 68 & $0.7(0.3-2.5)$ \\
Obstructive & 8 & $27.0(15-49)$ & 66 & $0.1(0.0-1.1)$ \\
\hline
\end{tabular}

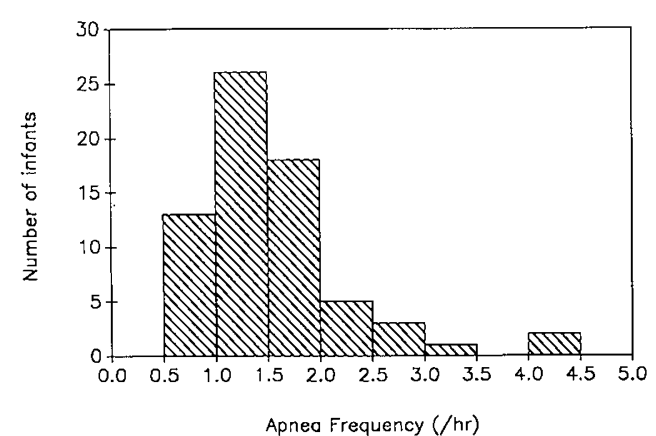

Fig. 1. Histogram showing the distribution of apneic spells among the infants.

ing 1110 significant apneic spells did not occur within $2 \mathrm{~min}$ after the end of an epoch of periodicity (Fig. 2).

Periodic breathing was not identified during the first $48 \mathrm{~h}$ of life in any of the 12 infants who were monitored early $(95 \%$ confidence intervals 0 to $25 \%$ ). All of the early monitored infants demonstrated significant apneic spells before $36 \mathrm{~h}$ of age $(95 \%$ confidence intervals 75 to $100 \%$ ).

Thirty-one of the 56 late monitored infants exhibited periodic breathing during the recordings taken before the first apneic spell, with an overall prevalence of $1.8 \%$. The prevalence of periodicity (in infants in whom it was detected) varied from 0.5 to $52 \%$ of the record, only two of the infants had a prevalence of more than $10 \%$.

The two infants with more than $10 \%$ periodicity exhibited this pattern for 25 and $52 \%$ of the recordings. In neither case was there significant apnea during the periodic epochs and in both cases the periodic breathing had ceased for more than $5 \mathrm{~min}$ before the first significant apnea.

The combined prevalence of periodic breathing for the two groups was $1.2 \%$ during the entire monitored interval before the first significant apnea. The prevalence was $0.13 \%$ during the two minutes immediately before apneic spells.

\section{DISCUSSION}

We investigated the common assertion that apnea of prematurity is associated with overt periodic breathing. Periodic breathing is usually defined as the regular recurrence of apneic spells of at least $2 \mathrm{~s}$ duration $(13,14)$ with intervening regular respirations, although some investigators require slightly longer apneas $(15,16)$. Some infants may demonstrate cyclical variations in tidal volume without actual apnea. This pattern of breathing has been investigated by Hathorn (17) and by Waggener et al. (18) using various filtering techniques. These techniques require the breath-to-breath calculation of minute ventilation by the use of a face mask and pneumotachograph. However, face masks stimulate ventilation $(19,20)$ and are not appropriate for long-term monitoring studies because of the increase in dead space that they cause (20). We have therefore used the noninvasive methodology of impedance pneumography, which clearly shows the presence or absence of chest wall movements, but does not correlate well with tidal volume because of the presence of chest wall distortion and upper airway obstruction in preterm infants.

Using this methodology, we have demonstrated that periodic 

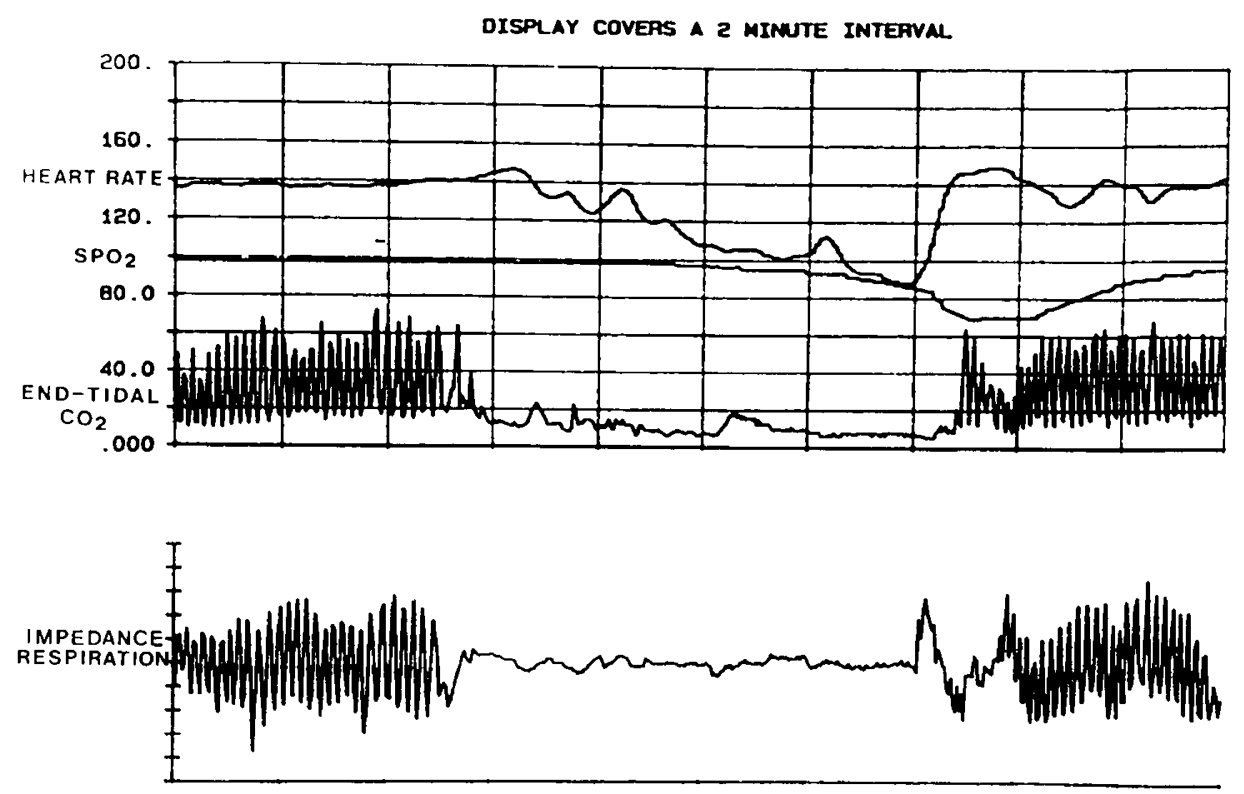

Fig. 2. Example of computer record of a prolonged central apnea occurring in a late monitored infants.

breathing does not precede significant apnea in preterm infants. This raises the question, why are our results diametrically opposed to those of Daily et al. (4)? Since the publication of that article there have been many significant changes in the practice of neonatology. Survival rates have improved remarkably, Daily's infants received neither intravenous nor oral glucose during the first $12 \mathrm{~h}$ of life, and arterial $\mathrm{PCO}_{2}$ and $\mathrm{pH}$ measurements were made on alternate days. Since the 1960 s, continuous mon itoring of oxygenation has become routine in neonatal care and the adjustment of $\mathrm{FIO}_{2}$ to maintain normal oxygenation is mandatory. In contrast, the infants described by Daily et al. (4) were cared for in "humidified oxygen between 21 (air) and $40 \%$. In the remaining two infants $96 \%$ oxygen was used."

Hypoxia can precipitate periodic breathing and eventually may lead to apnea because of central respiratory depression (21). We, therefore, assume that the difference between the previous investigation of Daily et al. (4) and the current study is that all of our babies were well oxygenated, whereas unsuspected mild or moderate hypoxia may have been prevalent in that previous study.

We have used a definition of significant apnea to limit our diagnosis of this entity to those spells that we believe are more likely to have detrimental sequelae. Apneic spells are commonly considered to be significant if they are prolonged (more than 10 or $15 \mathrm{~s}$ ) or if associated with hypoxia or bradycardia (22). We required both a duration of more than $15 \mathrm{~s}$ and the presence of hypoxia or bradycardia in order for an apnea to qualify as significant. Thus, all of the spells that we considered significant would have been included in the more commonly used definitions of apneic spells, but we did not include those spells that were not associated with a reduction in oxygen delivery.

We do not routinely perform EEG in infants who have apneic spells and it is therefore possible that some of the apneic spells that we examined were apneic seizures. However, convulsive apnea in preterm infants appears to infrequently occur in conjunction with bradycardia (23), presumably because such apneas tend to be shorter. It would, therefore, have been very unusual for a convulsive apnea to satisfy our criteria of significance.

Significant apneic spells were universal during the first $36 \mathrm{~h}$ of life in the 12 early monitored infants, $(95 \%$ confidence intervals $=75$ to $100 \%$ of infants) and in none of these infants was any underlying etiology other than prematurity discovered. Although Henderson-Smart described early apnea in preterm babies (24), his methodology was not reported in any detail and his findings have not become standard in neonatal texts. Current teaching therefore suggests that idiopathic apnea during the first $24 \mathrm{~h}$ is uncommon $(2,25-27)$, and it is, therefore, considered more likely to be "pathologic" and a vigorous search for precipitating factors is usually initiated (25). We have demonstrated that intensively monitored infants will almost certainly have significant apnea of prematurity documented before $36 \mathrm{~h}$ of age, and will usually have no underlying etiology detectable.

We have shown that periodic breathing did not occur during the first $48 \mathrm{~h}$ of life, a result that is consistent with the findings of Fenner et al. (28). The 95\% confidence intervals for this result include the possibility that $25 \%$ of premature infants experience periodicity during the first $48 \mathrm{~h}$, and thus this result will require further confirmation. It appears that full-term infants also have a very low incidence of periodic breathing immediately after birth, the frequency increasing thereafter until $1 \mathrm{wk}$ of age and then gradually decreasing (29).

Two recent studies involving human subjects have increased our understanding of the role of chemosensitivity in the pathogenesis of periodic breathing. Hackett et al. (30) studied adults who were spontaneously exhibiting periodicity at an altitude of $4400 \mathrm{~m}$. Subjects who then received acetazolamide, which stimulates the central chemoreceptor by preventing the alkalinization of the cerebrospinal fluid, had a significant reduction in periodic breathing. In contrast, when they received almitrine, a peripheral chemoreceptor stimulant that augmented the ventilatory response to hypoxia, periodic breathing increased. With either drug, ventilation was increased overall, and arterial oxygen saturation improved. Chapman et al. (31) were able to induce periodic breathing in volunteers by administering a hypoxic mixture when the subjects were wearing an apparatus that increased the gain of the hypoxia control loop, demonstrating that periodic breathing can be driven by the hypoxia responsive chemoreceptors when the stability of the negative feed back loop is decreased.

There is controversy concerning the activity of the carotid chemoreceptors before birth, which depends to some extent on the experimental model used $(32,33)$. However, there is some agreement that immediately after delivery the carotid bodies are suppressed, and gradually achieve their usual hypoxic responsiveness thereafter $(24,34)$. The exact time course of this "resetting" of the peripheral chemoreceptors is not clear. The absence of periodicity in the first $48 \mathrm{~h}$ of life suggests that the peripheral chemoreceptor is inactive during this time period in the premature infant. 
Sleep state may influence the effects of the peripheral chemoreceptors. It has been shown in newborn lambs that the response to carotid body stimulation is suppressed during rapid eye movement (active) sleep (35). Periodic breathing is more common in quiet sleep (36), whereas apneas may be more common in active sleep (37), and preterm infants spend a greater portion of their sleep time in active sleep (38). We did not monitor infants extensively enough to determine sleep states in this study.

We have clearly demonstrated that periodic breathing does not precede idiopathic apnea of prematurity in a group of infants who all had significant apnea by our definition. This suggests that the mechanisms underlying the two respiratory patterns are mutually exclusive, and supports our original contention that periodic breathing requires an active carotid chemoreceptor that may also act to terminate apneic spells before they become significant.

\section{REFERENCES}

1. Volpe JJ, Hill A 1987 Neurologic disorders. In: Avery GB (ed) Neonatology: Pathophysiology and Management of the Newborn. JB Lippincott Co, Philadelphia, pp 1073-1132

2. Harper RG, Yoon JJ 1987 Handbook of Neonatology. Year Book Medical Publishers, Chicago

3. Brazy JE, Kinney HC, Oakes WJ 1987 Central nervous system structura lesions causing apnea at birth. J Pediatr 111:163-175

4. Daily WJR, Klaus M, Meyer HBP 1969 Apnea in premature infants: monitoring, incidence, heart rate changes, and an effect of environmental temperature. Pediatrics 43:510-518

5. Wennergren G, Wennergren M 1983 Neonatal breathing control mediated by the central chemoreceptors. Acta Physiol Scand 119:139-146

6. Khoo MCK, Kronauer RE, Srohl KP, Slutsky AS 1982 Factors influencing periodic breathing in humans: a general model. J Appl Physiol 53:644-659

7. Bowes G, Townsend ER, Kozar LF, Bromley SM, Phillipson EA 1981 Effect of carotid body denervation on arousal responses to hypoxia in sleeping dogs. J Appl Physiol 51:40-45

8. Fewell JE, Baker SB 1987 Arousal from sleep during rapidly developing hypoxaemia in newborn lambs. Pediatr Res 22:471-478

9. Dejours P 1962 Chemoreflexes in breathing. Physiol Rev 42:335-358

10. Hertzberg T, Lagercrantz H 1987 Postnatal sensitivity of the peripheral chemoreceptors in newborn infants. Arch Dis Child 62:1238-1241

11. Barrington KJ, Finer NN, Wilkinson MW 1987 Progressive shortening of the periodic breathing cycle duration in newborn infants. Pediatr Res 21:247251

12. Muttit SC, Tierney AJ, Finer NN 1988 The dose response relationship of theophylline in the treatment of apnea of prematurity. J Pediatr 112:115121

13. Waite SP, Thoman EB 1982 Periodic apnea in the full-term infant: individual consistency, sex differences and state specificity. Pediatr 70:79-86

14. Carse EA, Wilkinson AR, Whyte PL, Henderson-Smart DJ, Johnson P 1981 Oxygen and carbon dioxide tensions, breathing and heart rate in normal Oxygen and carbon dioxide tensions, breathing and heart rate

15. Kelly DH, Walker AM, Cahen L, Shannon DC 1980 Periodic breathing in siblings of sudden infant death syndrome. Pediatrics 66:515-520.

16. Hoppenbrouwers T, Hodgman JE, Harper RM, Hofmann E, Sterman MB
McGinty DJ 1977 Polygraphic studies of normal infants during the first six months of life: III. Incidence of apnea and periodic breathing. Pediatrics $60: 418-425$

17. Hathorn MKS 1978 Analysis of periodic breathing in full term infants. J Physiol 285:85-89

18. Waggener TB, Stark AR, Cohlan BA, Frantz ID 1984 Apnea duration is related to ventilatory oscillation characteristics in newborn infants. $J$ Appl Physiol 57:536-544

19. Fleming PJ, Levine MR, Goncalves A 1982 Changes in respiratory pattern resulting from the use of a face mask to record respiration in newborn infants. Pediatr Res 16:1031-1034

20. Dolfin T, Duffty P, Wilkes D, England S, Bryan H 1983 Effects of a face mask and pneumotachograph on breathing in sleeping infants. Am Rev Respir Dis 128:977-979

21. Rigatto H, Brady JP 1972 Periodic breathing and apnea in preterm infants II Hypoxia as a primary event. Pediatr 50:219-227

22. Martin RJ, Miller MJ, Carlo WA 1986 Pathogenesis of apnea in preterm infants. J Pediatr 109:733-741

23. Fenichel GM, Olson BJ, Fitzpatrick JE 1980 Heart rate changes in convulsive and non-convulsive neonatal apnea. Ann Neurol 7:577-582

24. Henderson-Smart DJ 1981 The effects of gestational age on the incidence and duration of recurrent apnoea in newborn babies. Aust Paediatr J 17:273276

25. Emmanouilides GC, Baylen BC 1988 Neonatal Cardiopulmonary distress. Year Book Medical Publishers, Chicago

26. Vyas $\mathrm{H}$, Milner $\mathrm{AD} 1986$ Other respiratory disorders in the neonate. In: Roberton NRC (ed) Neonatology. Churchill Livingstone, Edinburgh, pp 312-339

27. Jose JH, Schreiner RL 1982 Neonatal Apnea. In: Schreiner RL, Kisling JA (eds) Practical Neonatal Respiratory Care. Raven Press, New York, pp 185202.

28. Fenner A, Schalk U, Hoenicke H, Wendenburg A, Roehling T 1973 Periodic breathing in premature and neonatal babies: incidence, breathing pattern, respiratory gas tensions, response to changes in the composition of ambient respiratory gas tensions, respo

29. Richards JM, Alexander JR, Shinebourne EA, de Swiet M, Wilson AJ, Southal DP 1984 Sequential 22-hour profiles of breathing patterns and heart rate in 110 full term infants during their first 6 months of life. Pediatrics 74:763777

30. Hackett PH, Roach RC, Harrison GL, Schoene RB, Mills WJ 1987 Respiratory stimulants and sleep periodic breathing at high altitude almitrine versus acetazolamide. Am Rev Respir Dis 135:896-898

31. Chapman KR, Bruce EN, Gothe B, Cherniack NS 1988 Possible mechanisms of periodic breathing during sleep. J Appl Physiol 64:1000-1008

32. Jansen AH, Ioffe S, Russell BJ, Chernick V 1981 Effect of carotid chemoreceptor denervation on breathing in utero and after birth. J Appl Physiol 51:630633

33. Blanco CE, Dawes GS, Hanson MA, McCooke HB 1984 The response to hypoxia of arterial chemoreceptors in fetal sheep and new-born lambs. Physiol 351:25-37

34. Belenky DA, Standaert TA, Woodrum DE 1979 Maturation of hypoxic ventilatory response of the newborn lamb. J Appl Physiol 47:927-930

35. Henderson-Smart DJ, Read DJC 1979 Ventilatory responses to hypoxaemia during sleep in the newborn. J Dev Physiol 1:195-208

36. Miller MJ, Carlo WA, DiFiore JM, Martin RJ 1988 Airway obstruction during periodic breathing in premature infants. J Appl Physiol 64:2496-2500

37. Gabriel M, Albani M, Schulte FJ 1976 Apneic spells and sleep states in preterm infants. Pediatr 57:142-147

38. Parmelee AH, Wenner WH, Akiyama Y, Schultz M, Stern E 1967 Sleep states in premature infants. Dev Med Child Neurol 9:70-77 